\title{
Memória e identidade: a musealidade no Museu Gruppelli, Pelotas/RS
}

\author{
Memory and identity: the musealidade in Gruppelli Museum, Pelotas/RS
}

\section{Memoria e identidad: el musealidade en Museo Gruppelli, Pelotas/RS}

\author{
José Paulo Siefert Brahm ${ }^{1}$ \\ Dr. Diego Lemos Ribeiro ${ }^{2}$ \\ Me. Davi Kiermes Tavares ${ }^{3}$
}

\begin{abstract}
Resumo
O presente artigo tem como referência uma pesquisa empírica que está sendo realizada no Programa de PósGraduação em Memória Social e Patrimônio Cultural, na Universidade Federal de Pelotas. O estudo busca identificar e analisar a percepção museal do público que visita as exposições do Museu Gruppelli, situado na zona rural de Pelotas, Rio Grande do Sul. Do mesmo modo, problematiza seu potencial de evocar memórias e forjar identidades, além de identificar que possíveis conexões o público cria ao flertar semanticamente com os objetos expostos. Como procedimento metodológico utiliza-se sobretudo a entrevista (presencial) e, igualmente, a observação do pesquisador. O roteiro da entrevista é semiestruturada, por meio de uma conversa com finalidade. Cumpre mencionar que as entrevistas estão sendo aplicadas ao público frequentador do Museu, sejam eles moradores da zona rural ou urbana, durante a visitação. De modo geral, a pesquisa aponta para o fato de que os objetos são responsáveis por ajudarem os entrevistados, pelo prisma da musealidade, a afirmarem identidades e evocarem memórias individuais e/ou coletivas, tanto pelo contato direto ou indireto que tiveram com os mesmos.
\end{abstract}

Palavras-Chave: Coleção, Lugares de memória, Identidade, Musealidade, Museu Gruppelli.

\section{Resumen}

El propósito de este artículo es establecer similitudes entre los términos tales como la historia, la memoria y la En este artículo se presenta brevemente una investigación empírica que se realizan en el Programa de Postgrado en la memoria social y el patrimonio cultural de la Universidad Federal de Pelotas. El estudio, que aquí se presenta, pretende identificar y analizar la eficacia de la percepción del museo al público que visitan las exposiciones de Gruppelli Museo situado en la zona rural de Pelotas, Rio Grande do Sul. Del mismo modo, se analiza su potencial para evocar recuerdos y forjar identidades e identificar las posibles conexiones que crea el

\footnotetext{
${ }^{1}$ Mestrando em Memória Social e Patrimônio Cultural; Universidade Federal de Pelotas - UFPel, Pelotas, Rio Grande do Sul, Brasil. josepbrahm@ @otmail.com

${ }^{2}$ Doutor em Arqueologia; Universidade Federal de Pelotas - UFPel, Pelotas, Rio Grande do Sul, Brasil. dlrmuseologo@yahoo.com.br

${ }^{3}$ Mestre em Memória Social e Patrimônio Cultural; Instituto Federal da Bahia - IFBA; Campus Eunápolis, Bahia, Brasil. dakita@uol.com.br
} 
público ligar con las exposiciones. Como se utiliza un procedimiento metodológico sobre todo la entrevista (en persona) y también la observación del investigador. La entrevista está semiestructurada, a través de una conversación con un propósito. Cabe mencionar que las entrevistas se están aplicando a museo aficionado ao público, si los residentes de zonas rurales o urbanas, durante la visita. En general, los puntos de la encuesta al hecho de que los objetos son responsables de ayudar a los encuestados, a través del prisma de musealidade afirmar identidades y evocar memorias individuales y / o colectivas, ya sea por contacto directo o indirecto que tenían con ellos.

Palabras claves: Colección, Lugares de la Memoria, Identidad, Musealidade, Museo Gruppelli.

\section{Abstract}

This paper presents briefly, an empirical research that is being carried out in the Graduate Program in Social Memory and Cultural Heritage of Federal University of Pelotas. The study, however presented, seeks to identify and analyze how effective the perception museal the public who visit the exhibitions of the Gruppelli Museum situated in the countryside of Pelotas, Rio Grande do Sul. In the same way, discusses its potential to evoke memories and forge identities, as well as to identify what possible connections the audience creates to flirt with the objects. As methodological procedure uses mainly the interview (in person), and also the observation of the researcher. The interview is half structured fashion, through a conversation with purpose. It should be mentioned that the interviews are being applied to the public the goer Museum, be they residents of rural or urban, during visitation. Overall, the research points to the fact that the objects are responsible for helping the respondents, through the prism of musealidade to affirm identities and summon up individual and/or collective memories, both by direct or indirect contact that they had with them.

Keywords: Collection, Memory seats, Identity, Musealidade, Gruppelli Museum.

\section{Introdução}

O presente artigo aborda o potencial dos museus como lugares de memória e identidade. Em um mesmo movimento, nem sempre dicotômico, compreendemos que essas instituições podem se consubstanciar, igualmente, como lugares de esquecimento, inseridos em esquemas de poder, de tensões e disputas sobre as memórias que serão representadas, algumas delas voluntariamente sublimadas. Vamos apresentar também, na forma de um estudo de caso, uma pesquisa que está sendo realizada no Programa de Pós-Graduação em Memória Social e Patrimônio Cultural da Universidade Federal de Pelotas. O estudo, ora apresentado, analisa a percepção museal do público que visita as exposições do Museu Gruppelli, situado na zona rural de Pelotas, Rio Grande do Sul, bem como seu potencial para evocar memórias e forjar identidades. Identifica, do mesmo modo, as conexões que o público cria ao flertar, semantizar e criar narrativas, tendo como plataforma de embarque os objetos expostos.

As técnicas de coleta de material para a realização da pesquisa foram pensados através de entrevista semi-estruturada, por meio de uma conversa de finalidade, elaborada pelo pesquisador, abordando questões abertas e fechadas (CRUZ NETO, 1994). Foram aplicadas 100 entrevistas ao público frequentador do Museu, tanto o morador da zona rural, como da zona urbana, durante a sua visita às exposições. Para Otávio Neto (1994), essa ferramenta 
possibilita "uma comunicação verbal que reforça a importância da linguagem e do significado da fala. Já, num outro nível, serve como um meio de coleta de informação sobre um determinado tema cientifico." (CRUZ NETO, 1994, p. 57). Ainda, para o autor, podemos obter dados objetivos e subjetivos, nos quais, o segundo busca identificar os valores, atitudes e opiniões dos entrevistados.

A formulação das perguntas feitas durante as entrevistas ao público foi pensada e elaborada com a intenção de responder os objetivos e questionamentos da pesquisa. Buscamos entender, ainda, os possíveis significados metafísicos que estão, em estado de latência, imbricados e emaranhados nas materialidades. Importante frisar, pela ótica deste artigo, que os objetos não são prenhes de significados, como se o valor fosse imanente; ao contrário, os esquemas de valoração dos objetos são potenciais, que podem desencadear, ou não, um processo de rememoração afetiva. Peter Van Mensch (1994) entende que a natureza dos objetos comporta dados intrínsecos e extrínsecos. Os dados intrínsecos estão associados a peso, dureza, forma, cor, textura, entre outros. Já os dados extrínsecos são referentes ao significado, função, valor estético, histórico, financeiro, simbólico, científico, entre outros.

Consideramos aqui um terceiro estrato: os sentidos que podem ser gerados, frutos da relação entre o sujeito e a cultura material; estes, por sua vez, são imensuráveis e mimetizáveis de acordo com as memórias e emoções que são desencadeadas secretamente no cognitivo do sujeito.

Para evitar a perda de dados, e potencializar a captura dos sentidos gerados pela interface sujeito-cultura material, fizemos uso de um caderno de campo. Nele, anotamos as principais observações, fatos, comentários, questionamentos, dúvidas, principais dados e algumas breves análises, que foram registrados durante e no final da realização das entrevistas. Este método é importante em pesquisas que buscam capturar o subjetivo, segundo o museólogo Diego Ribeiro (2012), na medida em que o pesquisador pode anotar e registrar os gestos e sentimentos durante suas entrevistas, observações e conversas.

No caminho de convergência entre objetividade e semântica, percebemos que o trabalho memorial é facilitado pela expressão física dos objetos; neste caso, a foice e a carroça, que serviram como gatilhos para evocação de memórias. Ao mesmo tempo, estes objetos servem como dispositivos que conectam o sujeito com realidades ausentes e com outros objetos - presentes ou não na exposição. (Ver figuras 1 a 4). 
RELACult - Revista Latino-Americana de Estudos em Cultura e Sociedade

Revista Latinoamericana de Estudios en Cultura y Sociedad | Latin American Journal of Studies in Culture and Society V. 02, Ed. Especial, dezembro, 2016, p. 684-705 | periodicos.claec.org e-ISSN 2016/Atual: 2525-7870 | e-ISSN 2015/2016: 2447-018X

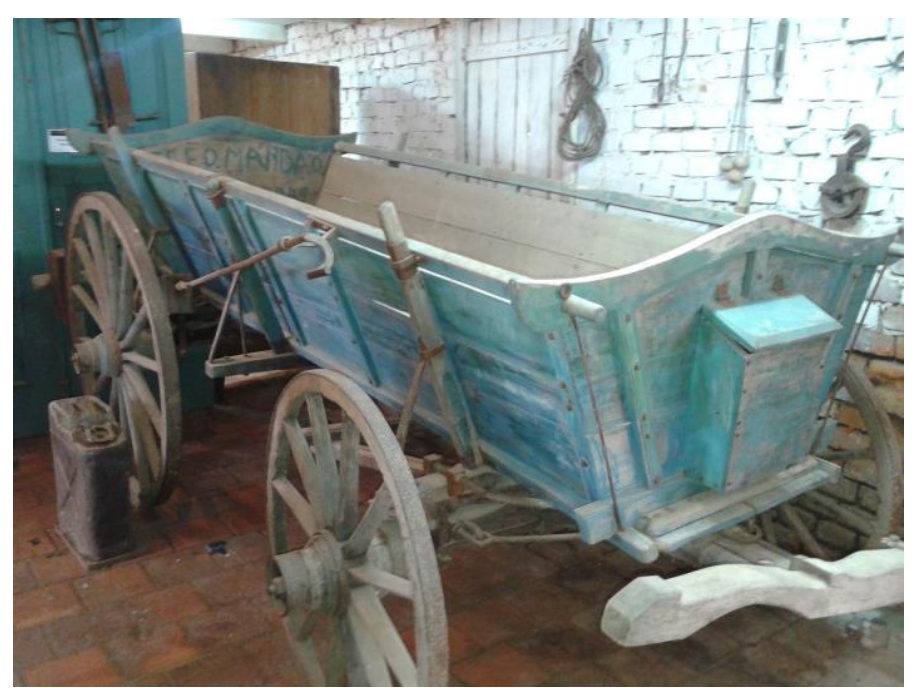

Fonte: Autores, 2015.

Figura 2 - Foice.

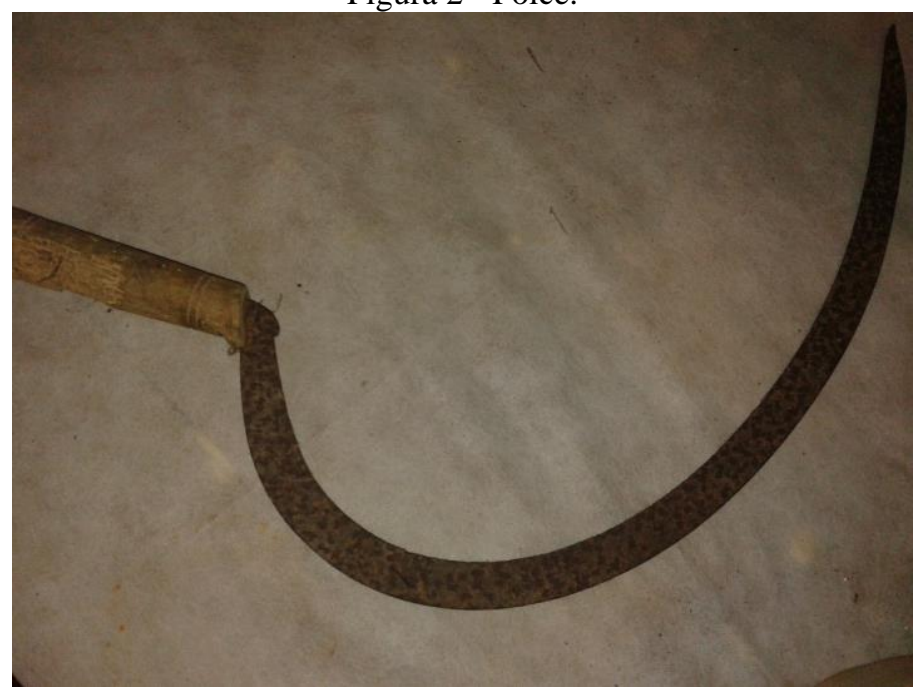

Fonte: Autores, 2015

Figura 3 - Carroça e foice no contexto expográfico do Museu Gruppelli.

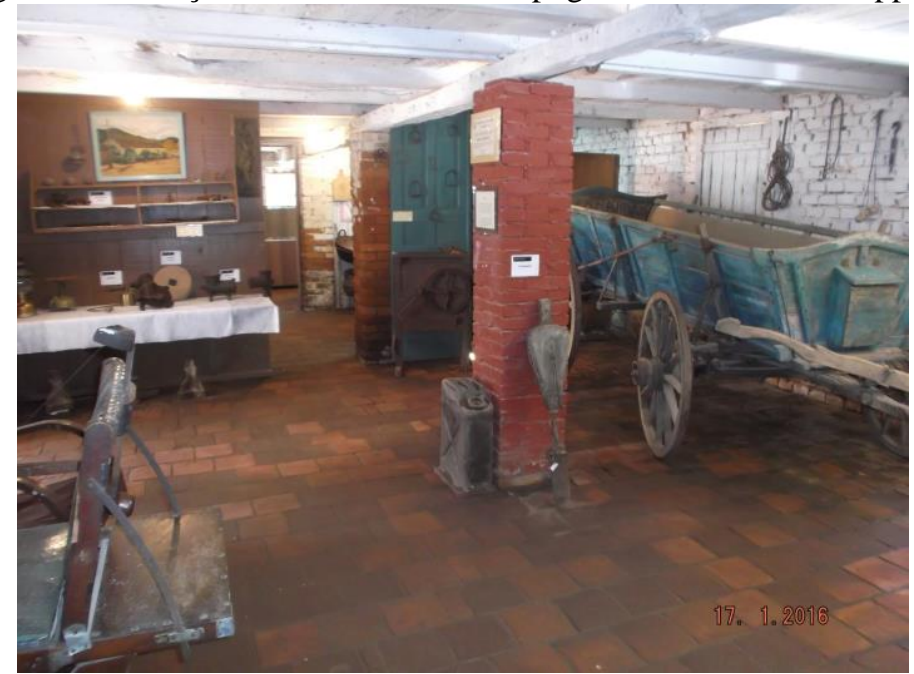

Fonte: Autores, 2016.

Figura 4 - Foice em contexto com outros objetos. 

e-ISSN 2016/Atual: 2525-7870 | e-ISSN 2015/2016: 2447-018X

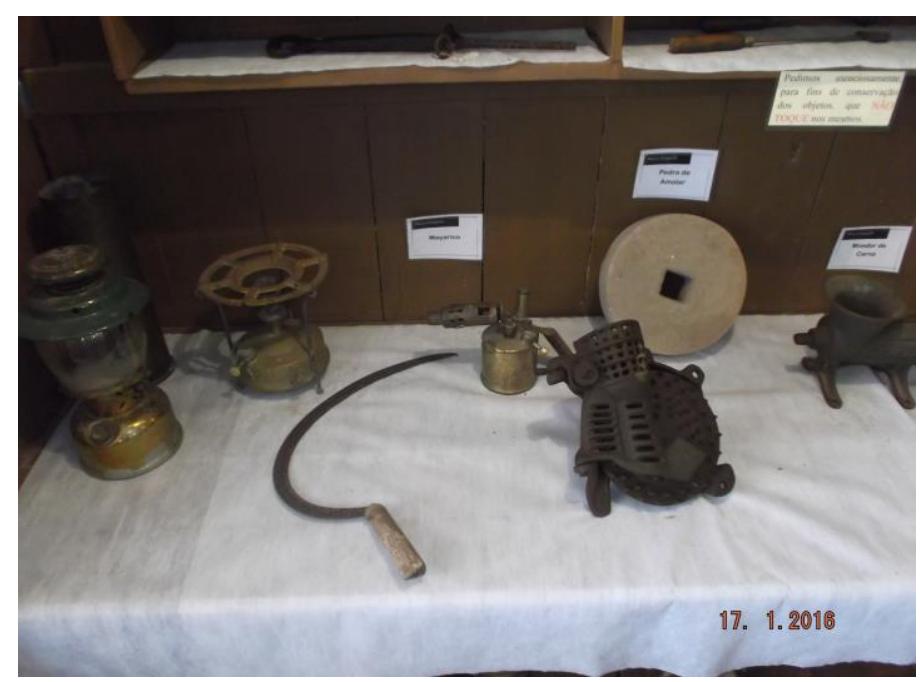

Fonte: Autores, 2016.

\section{A questão da musealidade}

$\mathrm{O}$ ato de colecionar objetos está intrinsecamente vinculado à formação dos museus no Ocidente. Mas, quais seriam os dispositivos sociais e cognitivos que motivam esse ato? Quais pontes conseguimos construir entre a formação de coleções e a vontade de preservar memórias? De forma sumária, compreendemos que a atribuição de valores e a recolha de objetos, base fenomenológica dos museus, está atrelada ao conceito de musealidade. Para Maria Cristina Bruno (2006), a musealidade seria a percepção contextual da cultura material, temporalmente localizada e culturalmente orientada, cujo objetivo final seria a preservação. Deste prisma, a percepção museal acompanharia a humanidade desde o início do processo de humanização, a partir do momento em que os grupos humanos selecionavam e retiravam fragmentos da realidade para proteção e guarda (BRUNO, 2006). Para a autora, a musealidade seria anterior ao próprio ato de colecionar e, consequentemente, anterior ao próprio museulugar.

Assim, reconhecemos que as atividades de observar, selecionar e valorizar, expor e guardar distingue a sociedade humana há milênios, dando origem ás ações do colecionismo que, por sua vez, permearam as rotas que levaram ao surgimento dos museus (BRUNO, 2006, p. 123).

Esse conceito é também sistematizado por Scheiner (2005), que entende que:

A musealidade é reconhecida por meio da percepção que os diferentes grupos humanos desenvolvem sobre esta relação, de acordo com os valores próprios de seus sistemas simbólicos. Como valor atribuído (ou assignado), a percepção (conceito) de 'musealidade' poderá mudar, no tempo e no espaço, ajustando-se aos diferentes sistemas representacionais de cada grupo social (SCHEINER, 2005, p. 95). 
Podemos dizer, para fins deste artigo, que a musealidade seria o deslocamento de olhares do observador sobre o universo material e sensível que o cerca (a cultura material), atribuindo-lhe novos estratos valorativos, de sentido e significado, cujo objetivo final seria a preservação e difusão de memórias que são fixadas nos objetos. Importante frisar, também, que essa percepção tem estrita relação com os processos de seleção e apropriação de referenciais de memórias, que, por serem imbuídos de intencionalidades, não estão desconectados das esferas de poder sobre os signos e os símbolos entrelaçados nos objetos.

Em um espectro simbólico, esses objetos são denominados por Pomian (1997) como semióforos: uma ponte entre o visível e o invisível. Os objetos quando ressignificados e insertados em um cenário de representação, o museu, servem como dispositivos que conectam o visível, pela objetividade dos objetos, ao invisível, pela subjetividade da percepção. Ao servir como ponte entre o aparente e o ausente, esses objetos assumiriam um valor documental da realidade para qual o observador é projetado. Tal como um rádio antigo que presentifica uma família ouvindo música em volta do artefato, mesmo que as pessoas imaginadas não estejam mais vivas. O mesmo rádio, em outro contexto de representação, pode orientar o observador a se projetar nas tecnologias do passado, quando um rádio a válvula era o ápice da engenharia. Enfim, todo esse espectro semântico está em latência, um valor residual, que aguarda o poder criativo de olhares interpretantes para "vir a ser". 4

Esse universo de significação é instrumentalizado e potencializado pelos processos de musealização, que animariam os objetos, no sentido de provê-los de "alma" (SILVEIRA; LIMA FILHO, 2005). São lhes atribuídos ainda uma nova utilidade, diferente da qual possuíam antes, novas funções e significados. "Também as formas de vida, atitudes, ações e experiências estão sujeitas a uma metamorfose parecida, quando saem do contexto, de uma atualidade viva e se tornam recordações.” (ASSMANN, 2011, p. 360). Os objetos de museus (musealia), então, devem ser vistos como possuidores de valores simbólicos, espirituais, de diversas matizes, como afirma Mário Chagas (2002).

\section{Os museus como lugares de memória e amnésia}

\footnotetext{
${ }^{4}$ Podemos relacionar essa afirmação ao conceito de virtualidade de Pierre Lévy. Para o autor, o virtual existe. Se realiza num processo de questionamento e problematização dos meios. "A virtualização pode ser definida como o movimento inverso da atualização [... é] uma mutação da identidade, um deslocamento do centro de gravidade ontológico do objeto considerado: em vez de se definir principalmente por sua atualidade (uma 'solução'), a entidade passa a encontrar sua consistência essencial num campo problemático.” (LÉVY, 1999, p. 17-18). "A palavra virtual vem do latim virtualis, derivado por sua vez de virtus, força, potência. Na filosofia escolástica, é virtual o que existe em potência e não em ato.” (LÉVY, 1999, p. 15).
} 

e-ISSN 2016/Atual: 2525-7870 | e-ISSN 2015/2016: 2447-018X

Assim como os objetos os próprios museus, no entendimento do Instituto Brasileiro de Museus (IBRAM), são instituições evocadoras de memória, de sensações, onde o público busca descobrir, aprender e ampliar seus conhecimentos e sua consciência de identidade. Maria Cristina Bruno (2006), na mesma direção, afirma que os museus são lugares que administram os indicadores de memória, tendo por desafio, por meio da salvaguarda e comunicação, criar representações e estimular reflexões sobre a realidade. "São lugares da memorização, tanto quanto esquecimento: são orientados para a consagração, valorização e preservação da herança patrimonial.” (BRUNO, 2006, p. 121).

Os museus podem ser compreendidos como lugares de memória, se os observarmos pelo prisma do historiador francês Pierre Nora (1993). Para o autor, esses lugares buscam preservar o passado no presente. Buscam preservar as lembranças de nossas vivências de outrora para a sua difusão. São mistos, híbridos, mutantes e em metamorfose, enlaçados de tempo e espaço, em memórias individuais e coletivas, do comum e do sagrado, do imóvel e do móvel. Possuem sentidos materiais simbólicos e funcionais, em justaposição. (NORA, 1993). Tal ideia é também defendida por Fleury e Walter (2011) ao afirmar que os museus desempenham a função de dispositivos memoriais que possibilitam a valorização, revalorização, reconstrução do passado no presente. “[...] museu não é mais (como se pensava há muito tempo) depositório de coisas velhas, sacralizadas, ícones, mas sim lugar de memória e da preservação da história e do patrimônio, que comunica“ (BERTOTTO, 2015, p. 56, grifo nosso).

Podem ser, ainda, locais de memórias. Assmann (2011), já citada, diz que existem diferenças conceituais entre o que é lugar e local. Para a autora, as memórias dos locais se diferenciam dos lugares de memória claramente. "É que enquanto a memória dos locais é fixada em uma posição determinada, da qual ela não se desprende, os lugares da arte da memória se distinguem justamente por se poder transferi-los" (ASSMANN, 2011, p. 332, 333). Em outros termos, firmados nessa ideia, podemos pensar nos museus não somente como lugares de memória, mas como locais de memória. Isso equivale pensarmos não somente nos museus tradicionais (edifícios readequados, ou construídos para esse fim, cujos acervos são deslocados para serem preservados), mas, referentes a todas suas múltiplas manifestações. Nessa lógica, podemos citar os museus de território, de cidade, sítios arqueológicos, cemitérios, paisagens, parques naturais musealizados, entre diversos outros. São acervos e coleções que permanecem e são mantidos no próprio espaço em que foram concebidos.

Os museus, como lugares e locais de memória (assim como os objetos), funcionam como "extensões de memória" (CANDAU, 2014). O sujeito recorre a esses lugares e locais 
para assegurar, reter suas memórias, porque sabe que não pode tudo lembrar. Trava, assim, uma luta contra a inevitabilidade do esquecimento. "Se habitássemos ainda nossa memória, não teríamos necessidade de lhe consagrar lugares" (NORA, 1993, p. 8), uma vez que esse lugar e local, por meio do trabalho museológico, "permeia o registro, objetiva a manutenção e revisão da memória, tornando-a o maior patrimônio" (MERLO; RAHME, 2015, p. 116). “[...]. O museu substancia memórias, posiciona os indivíduos e os grupos sociais, dá pistas para entendermos sentidos e sentimentos no âmbito do público e do privado." (MERLO; RAHME, 2015, p. 121).

O museu, dessa forma, assume o lugar de guardião no sentido de preservar e difundir em momentos e de forma oportuna, com estudos e cuidado, tornando o privado algo que o público pode compreender com ética e aprender com a experiência única do cotidiano vivido - centro de pesquisa e difusão da história viva (MERLO; RAHME, 2015, p. 119).

Segundo Scheiner (2005), os museus estão articulados aos mais essenciais meios de expressão da memória: o tempo, a língua e o espaço. É nessa relação de elementos em que a instituição opera. Para a autora, a memória pode ser entendida como um processo, enquanto jogo de articulações da emoção e da mente humana. Ideia partilhada por Jelin (2002), que afirma que a memória seria um processo subjetivo ancorado em experiências e marcas simbólicas e materiais. É preciso reconhecer a memória como objeto de disputas, conflitos e lutas, em que os participantes estão relacionados com os dispositivos do poder. A memória é um importante mecanismo cultural para fortalecer o sentimento de pertencimentos dos diferentes grupos. Em outras palavras, cabe aos museus, segundo Scheiner (2005), representar as expressões, valores e desejos do sujeito, a partir de suas realidades percebidas, atuando nos diferentes planos de memória. O que é corroborado por Junior e Tostes (2008), quando afirma que:

Os museus possuem uma relação estreita com os acervos que abrigam, possibilitando, através de cada objeto, uma variedade de informações sobre as ações produzidas pelos homens. No entanto, devem ser entendidos não apenas como uma coleção dos testemunhos materiais do passado, mas também como elementos de identificação e referência da vida presente. Nos museus, o ontem e o hoje caminham juntos, evidenciado as tensões e as relações entre passado e presente, memória e esquecimento (JÚNIOR, TOSTES, 2008, p. 7).

Chagas (2002), ainda no campo das tensões, afirma que os museus são responsáveis por construir um discurso sobre a realidade, ligados a um complexo esquema de lembrança e esquecimento, tanto do enunciado, como das suas lacunas, desde a concepção e planejamento, até a extroversão dos discursos museais. Cumpre mencionar que é, sobretudo, na exposição 
onde os objetos são trazidos ao olhar do público, e é nela que se decidirão os discursos que serão lembrados e os que serão jogados a escuridão do esquecimento.

Interessa compreender que a exposição do acervo vincula-se a um determinado discurso, a um determinado saber dizer. Assim, ao dar maior visibilidade ao acervo o que se faz é afirmar ou confirmar um discurso. O que se expõe à visão do vigia não são objetos, são falas, narrativas, histórias, memórias, personagens em cela, em cena e em cera, acontecimentos congelados. Neste caso, o que se quer aprisionar e ao mesmo tempo deixar à vista é a memória, a história, a verdade, o saber (CHAGAS, 2002, p. 56).

O autor em pauta:

Isso implica falar em forças de tensão entre poder e memória. A memória voluntária ou involuntária, individual ou coletiva - é, como se sabe sempre seletiva. O seu caráter seletivo deveria ser suficiente para indicar as suas articulações com os dispositivos do poder (CHAGAS, 2002, p. 44).

Desse modo, ainda com o mesmo autor, os museus, como cenários de representações, podem ser um espaço usado para apagar voluntariamente memórias e, ao mesmo tempo, para consolidar lembranças (CHAGAS, 2002). E ele destaca que a utilização do poder, muitas vezes, pelas classes dominantes, pode impor um discurso "verdadeiro" sobre os dominados, se utilizando do passado, sem a chance de releitura. Podemos supor, então, que os museus podem estar inseridos em um "conflito em torno de uma memória coletiva", conceito confeccionado por Candau (2004). Isso ocorre quando há a tentativa de se consolidarem certas lembranças, em detrimento de outras, por grupos mais favorecidos, havendo, assim, uma tentativa de apagamento de memórias dos fatos ocorridos, ou mesmo, forçando-as ao esquecimento.

Na mesma toada, a partir de Ricoeur (2007), compreendemos que muitas imagens são impedidas de serem reconstruídas, configurando-se em um esquecimento impositivo. "Muitos esquecimentos devem ao impedimento de ter acesso ao tesouro enterrados da memória." (RICOEUR, 2007, p. 452). Não raro, é no "caminho da recordação que se encontra os obstáculos para o retorno da imagem.” (RICOEUR, 2007, p. 452). Para ele, é impossível lembra-se de tudo, também é impossível tudo narrar, e que essa narrativa é composta de uma dimensão seletiva.

[...] a ideologização da memória é possibilitada pelos recursos de variação que o trabalho de configuração narrativa oferece. As estratégias do esquecimento enxertam-se diretamente nesse trabalho de configuração; pode-se sempre narrar de 

e-ISSN 2016/Atual: 2525-7870 | e-ISSN 2015/2016: 2447-018X

outro modo, suprimindo, deslocando as ênfases, refigurando diferentemente os protagonistas da ação assim como os contornos dela (RICOEUR, 2007, p. 455).

Afirma também que:

O perigo maior, no fim do percurso, está no manejo da história autorizada, imposta, celebrada, comemorada - da história oficial. $\mathrm{O}$ recurso à narrativa torna-se assim a armadilha, quando potências superiores passam a direcionar a composição da intriga e impõe uma narrativa canônica por meio de intimidação ou de sedução, de medo ou de lisonja. Está em ação aqui uma forma ardilosa de esquecimento, resultante do desapossamento dos atores sociais de seu poder originário de narrarem a si mesmos (RICOEUR, 2007, p. 455).

Trata de um esquecimento obrigado, no qual os atores sociais não podem narrar sua própria história. Se evita que as memórias sejam recordadas e revindicadas, se trata não só de um esquecimento "semi ativo", como também, "semi passivo" (RICOEUR, 2007).

Le Goff (1990), dando continuidade a esse pensamento, diz que a busca da manipulação da memória coletiva é uma maneira encontrada pelos grupos dominantes na tentativa de apagá-la e silenciá-la para a sua manipulação.

Do mesmo modo, a memória coletiva foi posta em jogo de forma importante na luta das forças sociais pelo poder. Tornarem-se senhores da memória e do esquecimento é uma das grandes preocupações das classes, dos grupos, dos indivíduos que dominaram e dominam as sociedades históricas. Os esquecimentos e os silêncios da história são reveladores desses mecanismos de manipulação da memória coletiva (LE GOFF, 1990, p. 368).

Partindo desse mesmo raciocínio, Paul Connerton (2008) afirma que o esquecimento repressivo aparace como uma das formas mais brutais do apagamento da memória. Ele pode ser utilizado pelas forças opressoras sem violência aparente, pode ser criptografado dissimuladamente. Não utiliza da força física, mas, meramente intelectual, semântica, a exemplo dos museus. ${ }^{5}$

Entretanto, Candau (2014), relativizando tal conceito, diz que as memórias tidas como homogêneas e unificadoras, usadas pelo Estado dominante para se apoderar e impor um discurso aos dominados (por meio dos museus, memoriais, celebrações, monumentos, entre

\footnotetext{
${ }^{5}$ O autor, baseado também em Duncan e Wallach (1980), cita como exemplo o Museu Metropolitan, em Nova York, no qual o públco que visita o grande salão da instituição fica na interseção de eixos principais. Na esquerda, se situa a coleção de arte grega e romana, à direita, a coleção egipcia e, à frente, na cimeira da grande escadaria que continua o eixo do entranceway, é a coleção de pinturas européias, começando com o Alto Renascimento. Para o autor, há um foco central na importância das coleções de arte ocidetal, para que seja lembrada pelo público visitante, entretando, as coleções destinadas a arte não ocidental, como a medieval, são invísiveis, a partir do Grande Hall. São evidentes, assim, as narrativas escolhidas e editadas na exibição das coleções, para aqueles que devem ser mais lembradas em detrimento de outras. Nesse espaço, também há uma luta da humanidade contra o poder e o esquecimento.
} 
outros) vêm se esvaziando devido à pluralidade dos grupos sociais a revindicarem suas memórias e identidades. E complementa: "as memórias contemporâneas seriam mosaico, sem unidade, feitos de fragmentos das grandes memórias organizadoras que foram despedaçadas, de pedaços compostos, restos divergentes, traços heterogêneos, testemunhos opostos, vestígios incoerentes." (CANDAU, 2014, p. 188).

Vemos, assim, baseados no autor utilizado acima, que cada sujeito, ou coletivo, em uma sociedade cada vez mais fragmentada, busca assegurar sua vitalidade, as suas memórias e identidades. Tenta identificar suas realidades na busca de reconstruir as memórias, não mais hegemônicas e unificadoras, mas, consolidar e organizar na esteira de um laço social, contrariando toda a ideia de submissão. Esses grupos veem os próprios centros culturais como um local onde possam trabalhar semanticamente suas memórias e identidades; fazem uso desses espaços como forma de realizarem uma releitura dos usos do passado no presente. Isso se deve ao fato de que a memória, segundo Jelin (2002), tem o potencial de exercer um importante papel como mecanismo cultural, para auxiliar no fortalecimento e sentimento de pertencimento dos grupos e comunidades.

Para Poulot (2013), caberia aos museus, na atualidade, atentarem à amnésia dos lugares, homens e coleções, evitando, desse modo, a consolidação de discursos excludentes, que não representam o grande público. Devem saber ajustar suas atividades aos condicionamentos do presente, se mantendo atualizados. “A atualização de seus sucessivos remanejamentos é uma tarefa que equivale a promessa de lucidez quando a sua reivindicação obstinada de autenticidade" (POULOT, 2013 p. 143). Os museus devem ser, desse modo, um "lugar de memória" (NORA, 1993), dando voz a todos os grupos, e não um "lugar de amnésia" (CANDAU, 2014), voltando seus discursos apenas para os seus detentores.

\section{O estudo de caso}

Como já mencionado anteriormente, para plasmar o conceito de musealidade em um panorama aplicado, vamos apresentar uma pesquisa empírica que está sendo realizada no Programa de Pós-Graduação em Memória Social e Patrimônio Cultural da Universidade Federal de Pelotas. O estudo em questão busca analisar a percepção museal do público que visita a exposição do Museu Gruppelli, bem como seu potencial para evocar memórias e forjar identidades, além de identificar que conexões o público cria ao flertar sensivelmente com os objetos expostos.

O Museu Gruppelli, inaugurado no ano de 1998, surge a partir da iniciativa da comunidade local que buscava preservar as suas histórias e memórias, tendo como referência 
os objetos que foram agrupados em forma de coleções. O Museu está localizado na zona rural de Pelotas, Rio Grande do Sul, no que se denomina Colônia Municipal. Possui um acervo de 2.000 objetos que são divididos em várias tipologias (esporte, doméstico, impressos, trabalho rural e trabalho especifico). Ele se apresenta como "um espaço de exposição e guarda de objetos que traduzem a 'vida na colônia', ou seja, as dinâmicas sociais de uma comunidade identificada pelas origens e trajetória imigrante" (FERREIRA; GASTAUD; RIBEIRO, 2013, p. 58). (Ver figuras 5 a 8).

Ao coletarem parcelas/fragmentos do real para fins de representação, aqueles atoressociais buscavam, a partir dos objetos, a representação dos modos de vida de um local, cuja carga significativa e simbólica atravessaria a objetividade material dos mesmos. A nosso ver, o processo de seleção e atribuição de valores aos referenciais de memória está vinculado ao que convencionamos chamar de musealidade. Em termos análogos, a musealidade redundaria no ato intencional, culturalmente orientado, de fixar e trabalhar a memória por intermédio de fragmentos da vida social (coleções).

É relevante frisar ainda que desde 2008 o Curso de Museologia da Universidade Federal de Pelotas (UFPel), por intermédio de projeto de extensão, vem colaborando com o Museu no sentido de provê-lo de caráter técnico-científico, mas, sobretudo, de ampliar seu potencial comunicativo, por intermédio de exposições e ações educativas.

Diversas ações foram feitas desde 2008 até o momento no Museu. Uma delas é a própria qualificação da exposição, que trouxe uma melhora à comunicabilidade, como a iluminação, a própria disposição e arrumação dos objetos, e a coleta de depoimentos. Comunicação que é considerada hoje a etapa mais importante do Museu. É na parte comunicativa que está a exposição de longa duração, as exposições temporárias. A última delas foi uma homenagem de noventa anos do Boa Esperança, time de futebol da colônia. Essas exposições temporárias temáticas são construídas com a participação de parcela da comunidade local, como no caso da exposição da costura e do futebol. Inclusive a atual exposição, que é sobre a enchente ${ }^{6}$ que assolou o Museu, se buscou também trabalhar com a comunidade local para interpretar como essa enchente atrapalhou não somente o Museu, mas a própria vida das pessoas que vivem nesse local.

\footnotetext{
${ }^{6}$ No sábado, dia 26 de março de 2016, a comunidade do sétimo distrito de Pelotas foi acometida por uma enchente de proporções inéditas. Casas e comércios da região sofreram enormes perdas. Com o Museu Gruppelli não foi diferente. Parte do acervo foi arrastado pela força da água, se perdeu ou foi danificado de forma irreversível. Entre as principais perdas do acervo está o tacho de cobre e a cadeira que ficava no cenário da barbearia.
} 
RELACult - Revista Latino-Americana de Estudos em Cultura e Sociedade

Revista Latinoamericana de Estudios en Cultura y Sociedad | Latin American Journal of Studies in Culture and Society V. 02, Ed. Especial, dezembro, 2016, p. 684-705| periodicos.claec.org e-ISSN 2016/Atual: 2525-7870 | e-ISSN 2015/2016: 2447-018X

No Museu vem se desenvolvendo ações educativas, sobretudo com crianças. Essa ação teria partido de uma curiosidade, de uma dúvida, uma vez que as crianças demonstraram grande interesse pelo Museu e gostam de visitar e brincar no local, enquanto que a vida fora dele está muito mais dinâmica, tendo como fator as tecnologias. A partir disso, vem sendo desenvolvida uma pesquisa dentro do Museu para entender o que chama a atenção dessas crianças nesse lugar. Como metodologia, foi solicitada que as crianças desenhassem de forma livre o que elas mais gostaram em relação ao Museu. Muitas dessas crianças retrataram não somente o Museu, mas a paisagem. Afirmando, assim, que o Museu não está isolado, mas que na verdade faz parte da paisagem. Ou seja, a paisagem ajuda a compor seu discurso. O Museu ainda tem investido na questão da internet, ao criar um perfil no facebook ${ }^{7}$. As pessoas tiram fotos dentro do Museu que são postadas na página. É uma forma sugerida para que as pessoas consigam se enxergar dentro do lugar. Como uma forma de compor a linguagem do Museu é realizada ainda uma série de atividades vinculadas a datas festivas, como dias das mães e dias das crianças, por exemplo.

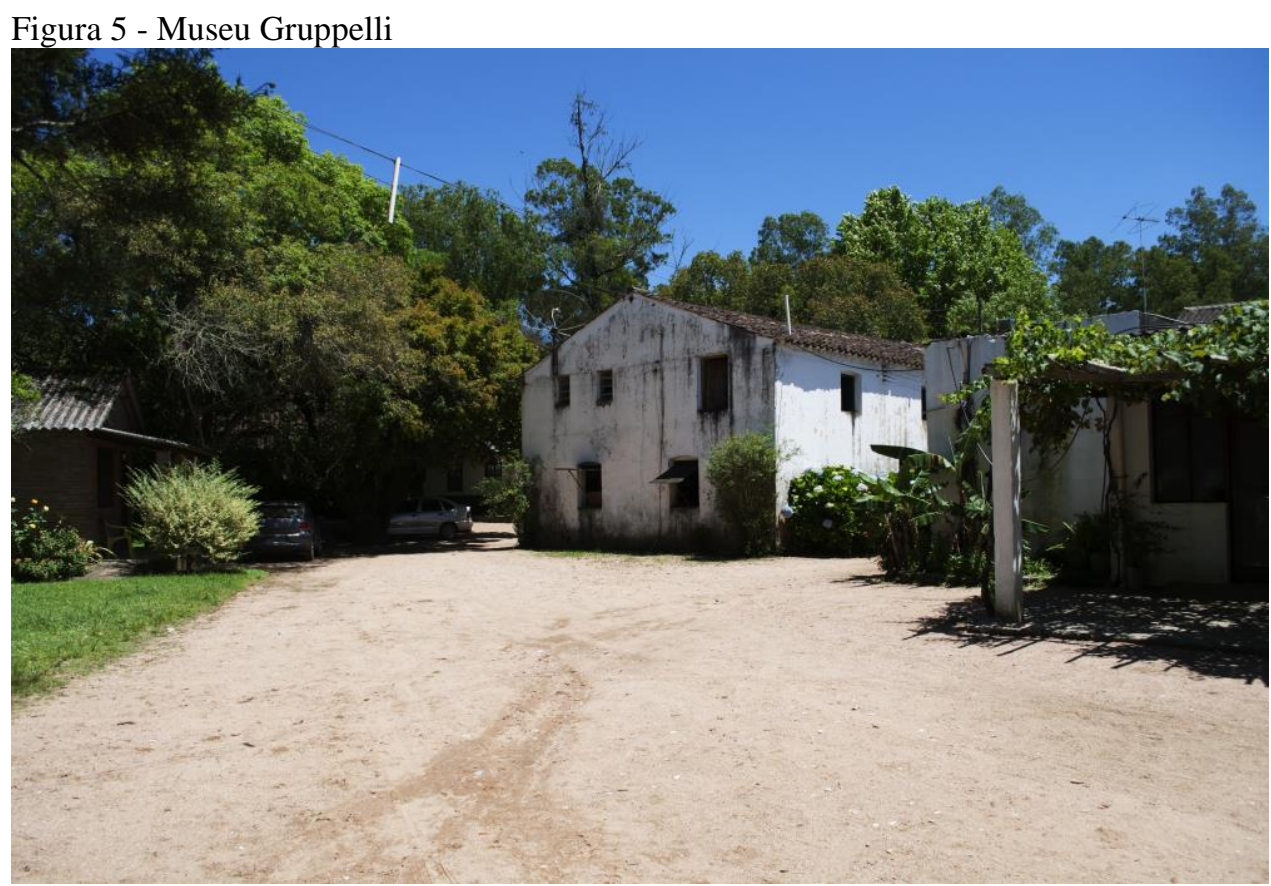

Fonte: Vinicius Kusma

Figura 6 - Entorno do Museu Gruppelli

\footnotetext{
${ }^{7}$ Página disponível em: <https://www.facebook.com/museugruppelli?fref=ts> Acesso em: 03 junho de 2016.
} 
RELACult - Revista Latino-Americana de Estudos em Cultura e Sociedade

Revista Latinoamericana de Estudios en Cultura y Sociedad | Latin American Journal of Studies in Culture and Society V. 02, Ed. Especial, dezembro, 2016, p. 684-705 | periodicos.claec.org e-ISSN 2016/Atual: 2525-7870 | e-ISSN 2015/2016: 2447-018X

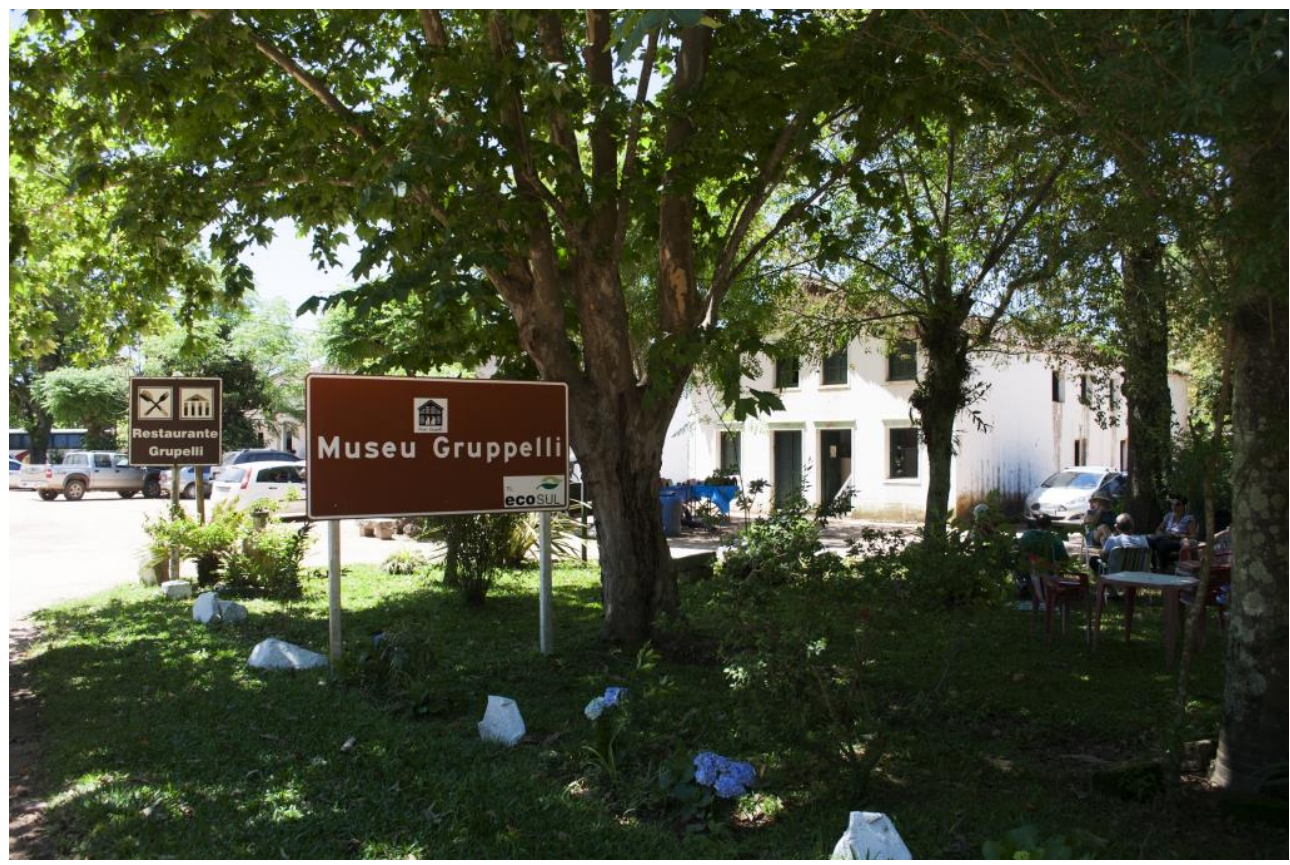

Fonte: Vinicius Kusma

Figura 7 - Representação da cozinha

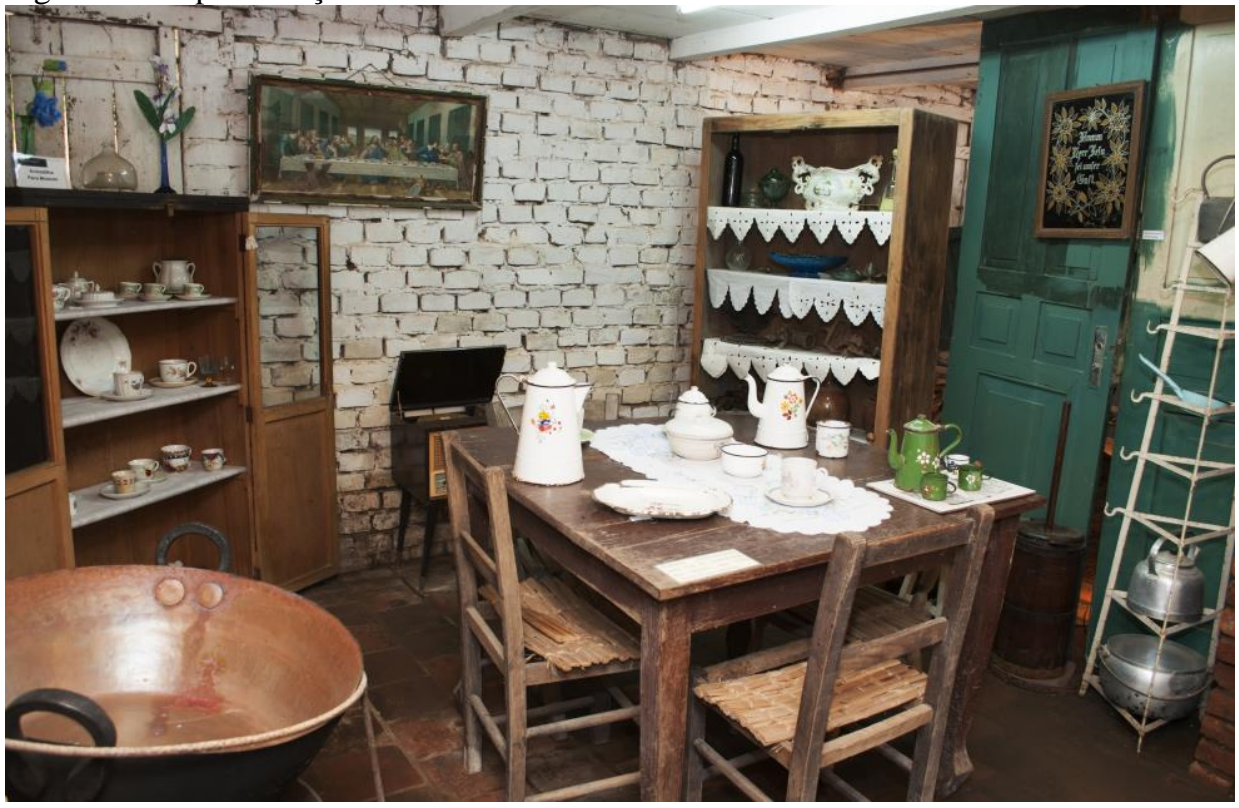

Fonte: Vinicius Kusma

Figura 8- Representação da barbearia 

e-ISSN 2016/Atual: 2525-7870 | e-ISSN 2015/2016: 2447-018X

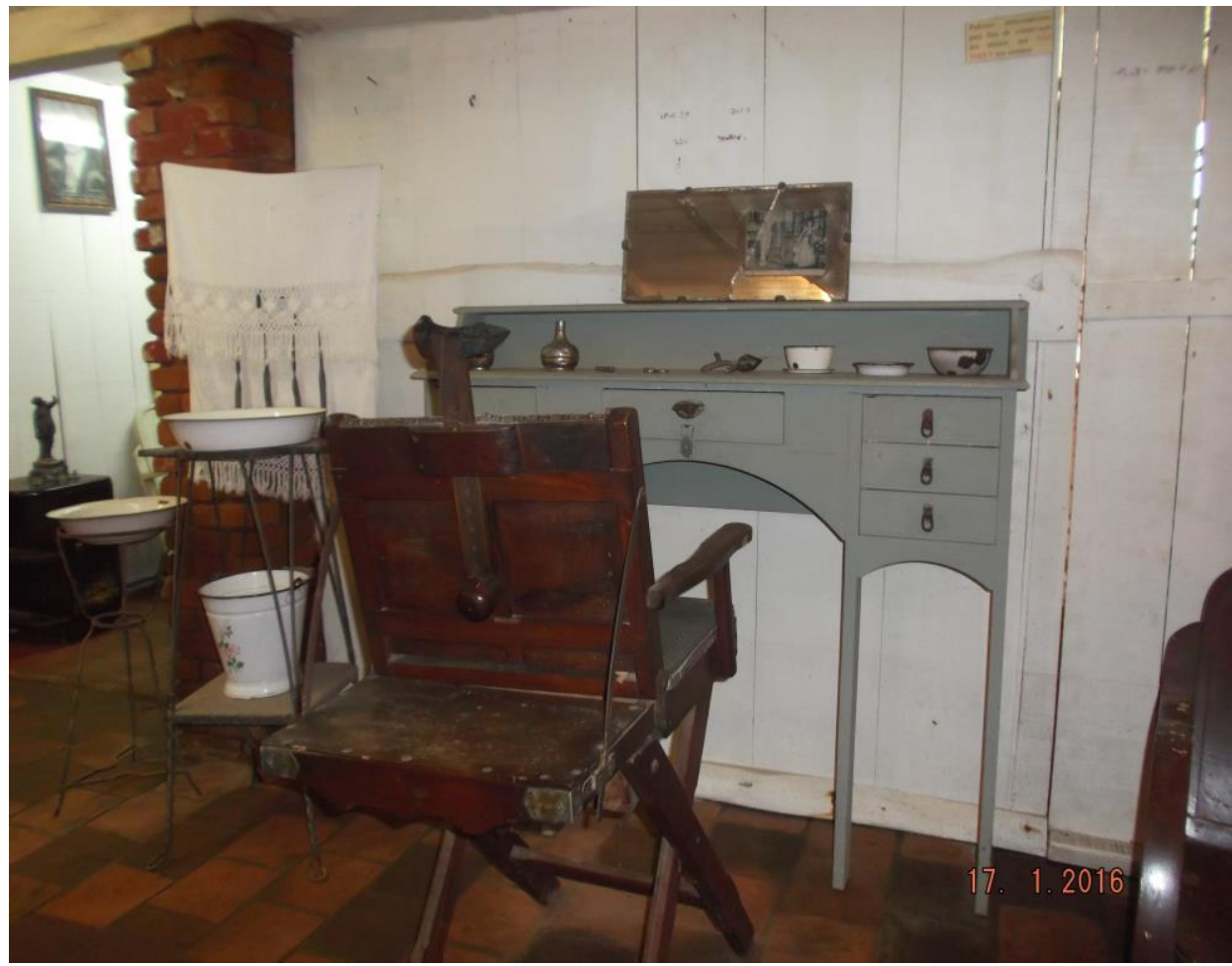

Fonte: Autores, 2016.

A pesquisa delineada ainda está em andamento, mas alguns dados e análises já podem ser observados. Foram aplicadas 100 entrevistas no Museu, no período de maio a setembro de 2015. Os visitantes foram convidados, pelo pesquisador, de forma aleatória, a participarem da pesquisa, após terem concluído a visita. Já outros entrevistados foram convidados quando o pesquisador percebia o interesse dos visitantes pelos objetos expostos.

Ao serem indagados se a carroça significava ou representava algo para si, 92 dos entrevistados disseram que sim. Desses, 57 lhes atribuíram um significado funcional (diz respeito à função inicial do objeto para a qual foi concebido). Entre os principais significados funcionais atribuídos pelos entrevistados à carroça, está o fato dessa ser vista como um objeto de passeio, trabalho e de transporte de pessoas, mercadorias e alimentos. Por outro turno, 35 dos entrevistados, atribuíram à carroça um significado representacional (significado que vai além da função utilitária do objeto). Entre os principais significados atribuídos ao objeto, está o fato de ser visto como representante da sua infância, (19 pessoas), da sua família, (7 pessoas), como símbolo da evolução social da época, (3 pessoas), seguidos das respostas do objeto lhe significar/representar um período de sacrifico no campo, por trazer lembranças da zona rural, por fazer parte da história, nostalgia, diversão, e por trazer recordações do período de trabalho, respectivamente, (1 pessoa cada).

Ao serem perguntados se o objeto lhes trazia alguma lembrança ao ser observado, 83 pessoas disseram que sim. As memórias evocadas pelo público entrevistado foram divididas 
em duas categorias: trabalho e ócio. Das 83 pessoas entrevistas que disseram que a carroça lhe traz alguma lembrança, 34 delas podemos classificar na categoria trabalho, seguido de 49 que podemos classificar na categoria ócio. Foi priorizada a categoria ócio por apresentar maioria absoluta de respondentes, embora determinado quantitativo também tenha indicado a categoria trabalho como concomitante, num total de 14 respostas.

Entre as memórias evocadas pelos entrevistados relacionadas à categoria "trabalho", podemos citar a utilização da carroça pelos entrevistados ou por outras pessoas, geralmente da própria família (pais, avós, tios) as quais, por demais das vezes, estavam acompanhados dos próprios entrevistados. Eles lembram que a carroça era utilizada para carregar lenha, os alimentos colhidos no campo (batata, cebola, abóbora, pêssego, feijão, pasto, trigo, milho) para casa, e, em alguns casos, levá-los para serem vendidos no comércio da cidade.

Já em relação às memórias evocadas relacionadas à categoria "ócio", podemos citar a utilização da carroça, por parte dos entrevistados, no período da infância como um objeto lúdico, para fins de passeio, seja para visitar familiares, para buscar frutas, ir aos bailes, tomar banho de arroio, ou mesmo, a utilizavam para o deslocamento de casa até a parada de ônibus mais próximo, para irem ao médico, aos jogos de futebol, à igreja, para fazerem compras na cidade. Lembram, também, de verem a utilização da carroça em filmes. Essas lembranças, quase sempre, eram evocadas relacionando aos membros da família (avós, pais, tios) que estavam presentes durante o tempo que ficavam utilizando o objeto.

Ao serem indagados se a foice significava ou representava algo para si, 85 dos entrevistados disseram que sim. Dessas, 74 lhes atribuíram um significado funcional (diz respeito à sua função inicial a qual foi concebido). Entre os principais significados funcionais atribuídos pelos entrevistados à foice, está o fato de terem relacionado a um objeto de trabalho, de corte de pasto, soja, trigo e macega. Por outro lado, 11 dos entrevistados atribuíram à foice um significado representacional (significado que vai além da função utilitária do objeto). Entre os principais significados atribuídos à foice, está o fato de a terem observado como um objeto perigoso (2 pessoas), sobrevivência, (2 pessoas), ligada à morte, ( 2 pessoas), seguindo de objeto que lhe traz lembranças, que representa o símbolo do trabalhador do campo, um objeto de brinquedo, que representa a infância e de aprendizado, respectivamente, (1 pessoa cada).

Já ao serem perguntadas se esse objeto lhes trazia alguma lembrança ao ser observado, 76 pessoas disseram que sim. Assim como em relação à carroça, as memórias evocadas pelo público entrevistado sobre a foice também foram divididas em duas categorias; trabalho e outros. Das 76 pessoas entrevistas que disseram que a foice lhe traz alguma lembrança, 71 
podemos classificar na categoria trabalho, seguidas de 5 que podemos classificar na categoria outros.

Entre as memórias evocadas relacionadas à categoria "trabalho", podemos citar a utilização da foice pelos entrevistados ou por outras pessoas, geralmente da própria família (pais, avós, tios) para o uso no campo, para o corte de pasto, soja, macega, trigo, arroz, alfafa, azevem, milho, aveia, para alimentar os animais que tinham em casa, como porco, vaca, galinha, cavalo, coelho. Lembram, ainda, de que a foice era utilizada para cortar alimentos para fins de produção/venda ou consumo próprio. As memórias oscilam entre o saudosismo, por não ser mais utilizada, e uma memória negativa, por indicar uma vida difícil no campo. Já em relação às memórias evocadas relacionadas à categoria "outros", podemos citar a menção dos entrevistados à foice como a um objeto que lembra a infância, um objeto perigoso e que foi visto em filmes de terror.

Com base nos dados acima, verificamos que os objetos (carroça e foice) funcionam como semióforos, apoiados em Pomian (1997), na medida em que conectam o visível ao invisível; criam conexões com pessoas, tempos e lugares distantes do olhar, que se presentificam simbolicamente. Ao observar este processo mnemônico pelo viés da musealidade, verificamos que os objetos expostos, principalmente a foice e carroça, levam os entrevistados a criarem conexões com o ausente, a convocarem ao presente o passado, e tecerem em uma mesma rede objetos, pessoas, lugares, mundos e tempos difusos.

Podemos afirmar por esse ponto de vista que os objetos podem ser inseridos aos quadros sociais da memória. De acordo com Halbwachs (1976), este conceito abarcaria a ideia de que a memória social modularia a nossa memória individual. "A representação das coisas evocadas pela memória individual não é mais do que uma forma de tomarmos consciência da representação coletiva relacionada as mesmas coisas" (HALBWACHS, 1990, p. 61). Ainda segundo o autor, os referidos quadros sociais consubstanciar-se-iam como influências externas que incidiriam na formatação das memórias, tais como a linguagem, família, religião, tempo e espaço nos quais estamos inseridos. O espaço, por seu turno, exerceria um dos mais importantes condicionantes para a fixação das lembranças, porque o sujeito não consegue reconstruir suas memórias se não estiverem vinculadas a determinado ambiente (HALBWACHS, 1976).

Silveira e Lima Filho (2005) partilham desta ideia ao mencionarem que os objetos sempre remetem a alguém, ou a algum lugar. Nas suas palavras: 

e-ISSN 2016/Atual: 2525-7870 | e-ISSN 2015/2016: 2447-018X

Um objeto ou coisa sempre remete a alguém ou algum lugar, permanecendo como um elemento de uma paisagem (o casarão do século XVIII; a velha figueira; o pilão; o Ford modelo 1929), ou mesmo de uma paisagem corporal (um colar de esmeraldas proveniente do Novo Mundo; um bracelete de ouro da Roma Antiga; um sapato à Luís XIV; um cocar Yanomami; um vestido de Marilyn Monroe). (2005, p. 39).

Nessa interface entre sujeito, objeto, lugar e memória, ainda complementam:

É nesse sentido que é possível falar numa memória que impregna e restitui “a alma nas coisas", referida a uma paisagem (inter)subjetiva onde o objeto (re)situa o sujeito no mundo vivido mediante o trabalho da memória, ou ainda, é da força e dinâmica da memória coletiva que o objeto, enquanto expressão da materialidade da cultura de um grupo social, remete à elasticidade da memória como forma de fortalecer os vínculos com o lugar, considerando as tensões próprias do esquecimento (2005, p. 39, grifo nosso).

Podemos dizer, então, que o objeto "fala sempre de um lugar, seja ele qual for, porque está ligado à experiência dos sujeitos com e no mundo, posto que ele representa uma porção significativa da paisagem vivida" (SILVEIRA; LIMA FILHO, 2005, p. 40). Sendo assim, os objetos são referência e consequências da construção cultural. Por materializar concepções culturais das mais diversas, que ajudarão a entender e compreender as dinâmicas sociais e culturais dos grupos, a qual está inserido (SILVEIRA; LIMA FILHO, 2005). Ao mesmo tempo podemos dizer que os objetos ajudam a moldar e consolidar o sujeito no presente, afirmando, ou reafirmando, suas memórias, bem como, quem ele foi, é e será.

Afirmamos ainda, que os objetos, ao serem apreendidos sensorial e semanticamente, são responsáveis por contribuírem para a consolidação de lembranças e para a afirmação das identidades do sujeito, uma vez que a memória está indissoluvelmente ligada à identidade das pessoas (CANDAU, 2014). Ou seja, é pelo prisma da musealidade que os entrevistados evocaram e fixaram suas memórias e afirmaram suas identidades, bem como, criaram as conexões para o invisível.

Vale mencionar, ainda, que, ao serem perguntados sobre os dois objetos centrais da pesquisa (carroça e foice), alguns entrevistados criaram algumas conexões com outros objetos, os quais haviam utilizados seja de forma direta ou indireta ${ }^{8}$. Em outras palavras, ao buscarem recordar sobre os objetos perguntados, os entrevistados criaram pontes que os levaram a lembrar de outros objetos que fizeram parte de sua vida.

Isso nos leva a pensar que os objetos funcionam em conexão, ou em redes, com outros. Ou seja, é importante destacar que as narrativas, a rigor, conectam os objetos selecionados

\footnotetext{
${ }^{8}$ Não usaram os objetos, mas viram seus pais, e avôs a utilizarem, mas que os marcou de certa forma.
} 
(foice e carroça) a outros que estão dentro ou fora do Museu, na forma de uma rede de relações simbólicas. Ideia que podemos ancorar no conceito Ator-Rede do antropólogo francês Bruno Latour (2012). Para o referido autor, os objetos podem estar imersos em uma rede de significações, inter-relações, onde humanos e não-humanos estão conectados, reciprocamente, de maneira horizontal, sem topologias. Isso ocorre, segundo John Law (2001) porque os objetos têm o poder de agir sobre os sujeitos. "The non-human just as much as the human may act. That agency does not necessarily belong to people" (LAW, 2001, p. 01). A partir desse ponto de vista, para Latour (2012), os não-humanos, ou seja, os objetos materiais, não devem ser considerados intermediários da relação com os humanos, mas, mediadores dessa relação. Nesse caso, os objetos, por meio da relação travada com os sujeitos, subsidiados pela musealidade, os ajudaram na construção de suas memórias, tanto individuais, como coletivas, ligando a tempos, pessoas e lugares distantes do olhar. Por outro lado, os próprios sujeitos ajudam na proteção e preservação dos objetos, considerados por si, importantes na manutenção de suas histórias e identidades.

\section{Considerações finais}

Vimos, nessa breve reflexão, que os museus, na contemporaneidade, buscam consolidar discursos mais heterogênios, voltados ao público e à sociedade, na consolidação de suas memórias e identidades. Os museus, a partir desse contexto, passam a pensarem menos em suas coleções, para pensarem mais em seus públicos, para se tornarem, assim, espaços mais dinâmicos, democráticos e comprometidos com sua função social.

Vimos ainda, que os objetos comportam dados intrínsecos e extrínsecos. Porém, podemos considerar aqui um terceiro estrato: os sentidos que podem ser gerados fruto da relação entre o sujeito e a cultura material; estes, por sua vez, são únicos, imensuráveis e mimetizáveis de acordo com as memórias e emoções que são desencadeados secretamente no cognitivo do sujeito. Essa constatação pode ser observada no estudo de caso aqui apresentado.

Podemos notar que os objetos são responsáveis por ajudarem os entrevistados, a partir da relação travada entre ambos, e pelo prisma da musealidade, a afirmarem suas identidades e evocarem suas memórias individuais e/ou coletivas, tanto pelo contato direto, ou indireto, que tiveram com os mesmos. Motivo que leva a compreender o Museu aqui pesquisado como um lugar de memória e identidade.

A musealidade possibilitou que os entrevistados percebessem os objetos pertencentes ao acervo do espaço para muito além de sua materialidade. Serviram, portanto, como dispositivos para a reconstrução e fixação das memórias, assim como instrumentos para 
(re)afirmar suas identidades. Funcionaram como conectores de tempos, espaços, mundos e pessoas próximas e distintas, trazendo o que está longe para perto, a morte para a vida, o ausente para o presente, o que estava no vácuo do esquecimento para a luz das recordações.

Por último, podemos dizer que a partir do conceito central de nossa pesquisa, compreendemos que o sujeito é um ser social que é moldado, diariamente, por influências externas a ele, que são praticamente imperceptíveis. Vimos que os objetos funcionam em rede com as pessoas e com outros objetos. Uma relação recíproca que define os objetos como parte insubstituível do sujeito, sendo verdadeiras "extensões de memórias" (CANDAU, 2014), espelhos que refletem seus usuários no presente e no futuro. Os objetos moldam o sujeito, assim como, por nós são moldados. É pela musealidade que os sujeitos valorizam os objetos, tendo, assim, vontade de preservá-los, difundi-los, no presente e no futuro, para as próximas gerações.

\section{Referências}

ASSMANN, Aleida. Espaços da recordação: formas e transformações da memória cultural. São Paulo: Editora da Unicamp, 2011.

BERTOTTO, Márica. Sistema museológico - contributo para as políticas públicas. In: GUIMARÃENS, Cêça; RANGEL, Vera; BERTOTTO, Márcia (Org.). Museologia social e cultural. Rio de Janeiro: Rio Book's, 2015.

BRUNO, Maria Cristina Oliveira. Museus e Pedagogia Museológica: os caminhos para a administração dos indicadores da memória. As várias faces do Patrimônio, por LEPA. Santa Maria: LEPA/UFSM, 2006.

Museologia: algumas ideias para a sua organização disciplinar. Centro de Estudos de sociomuseologia. Lisboa: Universidade Lusófona de Humanidades e Tecnologias, Cadernos de Sociomuseologia, n. 9. 1996.

CANDAU, Joel. Memória e Identidade. São Paulo: Contexto, 2014.

Conflits de mémoire: pertinence d'une métaphore? In: BONNET, V'Wronique (sous la direction de) Conflits de mémoire. Paris: Éditions Karthala, 2004.

CONNERTON, Paul. Seven types of forgetting. Memory Studies, 2008, p. 1- 59.

CRUZ NETO, Otávio. Trabalho de campo como descoberta e criação. In: MINAYO, Maria Cecília de Souza (Org). Pesquisa social: teoria, método e criatividade. Petrópolis, RJ: Vozes, 1994.

CHAGAS, Mario de Souza. Memória e Poder: dois movimentos. Cadernos de Sociomuseologia, n.19, p. $35-67,2002$. 

e-ISSN 2016/Atual: 2525-7870 | e-ISSN 2015/2016: 2447-018X

FERREIRA, Maria Leticia; GASTAUD, Carla; RIBEIRO, Diego Lemos. Memória e emoção patrimonial: Objetos e vozes num museu rural. Museologia e Patrimônio, v. 6, p. 57-74, 2013.

FLEURY, Beatrice; WALTER, Jacques. De los lugares de sofrimiento a su memoria In: FLEUR y Béatrice; WALTER, Jacques (comps) Memorias de la piedra. Ensayos en torno a lugares de detención y masacre. Ed. Ejercitar la memoria, 2011.

HALBWACHS, Maurice. Les cadres sociaux de la mémoire. Paris: Mouton, 1976. . A memória coletiva. Rio de Janeiro, Vertice, 1990.

Instituto Brasileiro de Museus (IBRAM). Disponível em: <http://www.museus.gov.br/museu/ >. Acesso em: 20 set. 2014.

JELIN, Elizabeth. Los trabajos de la memoria. España: Siglo Veintiuno editores, 2001.

LATOUR, Bruno. Reagregando o Social: uma introdução à teoria do Ator-rede. Salvador: Edufba, 2012, São Paulo: Edusc, 2012.

LAW, John. Ordering and obduracy. Centre for Science Studies. Lancaster University, 2001. Disponível em: <http://www.lancaster.ac.uk/fass/resources/sociology-onlinepapers/papers/law-ordering-and-obduracy.pdf> Acesso em: 26 dez. 2015.

LE GOFF, Jacques. História e Memória. Campinas: Editora da Unicamp, 1990.

LÉVY, Pierre. O que é o virtual? São Paulo: Editora 34, 1999.

MENSCH, Peter Van. O objeto de estudo da museologia. Rio de Janeiro: UNIRlO/UGF,1994.

MERLO, Márcia; RAHME, Anna Maria. A moda e o museu: uma experiência no espaço digital. In: MERLO, Márcia (Org.). Memórias e museus. São Paulo: Estação das Letras e Cores, 2015.

NASCIMENTO JÚNIOR, José do; TOSTES, Vera Lúcia Bottrel. A democratização da memória: a função social dos museus ibero - americanos. In: CHAGAS, Mário de Souza; BEZERRA, Rafael Zamorano; BENCHETRIT, Sarah Fassa. (Org). A democratização da memória: a função social dos museus ibero - americanos. Rio de Janeiro: Museu Histórico Nacional, 2008, p. 7-8.

NORA, Pierre. Entre memória e história: a problemática dos lugares. Projeto História. Revista do Programa de Estudos Pós-Graduados em História e do Departamento de História da PUCSP, n. 10, p. 7-28, 1993.

POULOT, Dominique. Museu e Museologia. Belo Horizonte: Autêntica editora, 2013.

POMIAN, Krzysztof. Coleção. In: VV. AA. Enciclopédia Einaudi 1: Memória-História. Lisboa: Imprensa Nacional Casa da Moeda, 1997. p. 51-86.

RIBEIRO, Diego Lemos. A musealização da Arqueologia: um estudo dos museus de arqueologia do Xingó e do sambaqui de Joinville. 2012, p. 376. Tese. (Doutorado em 
Arqueologia) Universidade de São Paulo, São Paulo, 2012. Disponível em: <http://www.teses.usp.br/teses/disponiveis/71/71131/tde-21052013-110733/pt-br.php>

Acesso em: 20 abr. 2015.

RICOEUR, Paul. A Memória, a História e o Esquecimento. Campinas : Edunicamp, 2007.

SCHEINER, Tereza. Museologia e pesquisa: perspectivas na atualidade. In: Museu de Astronomia e Ciências Afins (Brasil). MAST Colloquia - Museu: Instituição de Pesquisa. Rio de Janeiro, 2005, p. 85 -100.

SILVEIRA, Flávio Leonel Abreu da; LIMA FILHO, Manuel Ferreira. Por uma antropologia do objeto documental: entre a "alma nas coisas" e a coisificação do objeto. Revista; Horizonte Antropológico, Porto Alegre, ano 11, n. 23, p. 37-50, jan/jun 2005. 